\title{
Effects of a multi-micronutrient-fortified beverage, with and without sugar, on growth and cognition in South African schoolchildren: a randomised, double-blind, controlled intervention
}

\author{
Christine Taljaard $^{1}$, Namukolo M. Covic ${ }^{1 *}$, Averalda E. van Graan ${ }^{1}$, Herculina S. Kruger ${ }^{1}$, \\ Cornelius M. Smuts ${ }^{1}$, Jeannine Baumgartner ${ }^{1}$, Jane D. Kvalsvig ${ }^{2}$, Hattie H. Wright ${ }^{1}$, \\ Martha E. van Stuijvenberg ${ }^{3}$ and Johann C. Jerling ${ }^{1}$ \\ ${ }^{1}$ Centre of Excellence for Nutrition, North-West University, Potchefstroom Campus, Private Bag X6001, Potchefstroom 2520, \\ South Africa \\ ${ }^{2}$ The Departments of Public Health Medicine and Psychology, University of KwaZulu-Natal, Howard College Campus, \\ Durban, South Africa \\ ${ }^{3}$ Nutritional Intervention Research Unit, Medical Research Council, Cape Town, South Africa
}

(Submitted 5 December 2012 - Final revision received 7 May 2013 - Accepted 10 May 2013 - First published online 4 July 2013)

\section{Abstract}

Little is known about the effects of combined micronutrient and sugar consumption on growth and cognition. In the present study, we investigated the effects of micronutrients and sugar, alone and in combination, in a beverage on growth and cognition in schoolchildren. In a $2 \times 2$ factorial design, children ( $n$ 414, 6-11 years) were randomly allocated to consume beverages containing (1) micronutrients with sugar, (2) micronutrients with a non-nutritive sweetener, (3) no micronutrients with sugar or (4) no micronutrients with a non-nutritive sweetener for 8.5 months. Growth was assessed and cognition was tested using the Kaufman Assessment Battery for Children version II (KABC-II) subtests and the Hopkins Verbal Learning Test (HVLT). Micronutrients decreased the OR for Fe deficiency at the endpoint (OR 0.19; $95 \%$ CI 0.07, 0.53). Micronutrients increased KABC Atlantis (intervention effect: 0.76; 95\% CI 0.10, 1.42) and HVLT Discrimination Index (1.00; $95 \%$ CI $0 \cdot 01,2 \cdot 00)$ scores. Sugar increased KABC Atlantis ( $0 \cdot 71 ; 95 \%$ CI $0 \cdot 05,1 \cdot 37)$ and Rover (0.72; $95 \%$ CI $0.08,1 \cdot 35)$ scores and HVLT Recall $3(0.94 ; 95 \%$ CI $0.15,1.72)$. Significant micronutrient $\times$ sugar interaction effects on the Atlantis, Number recall, Rover and Discrimination Index scores indicated that micronutrients and sugar in combination attenuated the beneficial effects of micronutrients or sugar alone. Micronutrients or sugar alone had a lowering effect on weight-for-age $z$-scores relative to controls (micronutrients $-0.08 ; 95 \%$ CI $-0.15,-0.01$; sugar $-0.07 ; 95 \%$ CI $-0.14,-0.002)$, but in combination, this effect was attenuated. The beverages with micronutrients or added sugar alone had a beneficial effect on cognition, which was attenuated when provided in combination.

Key words: Anthropometric status: Child micronutrient status: Cognitive function: Sugar

The most recent South African National Food Consumption Survey-Fortification Baseline (NFCS-FB) in 2005 reported that almost $14 \%$ of South African children aged 1-5 years were vitamin A deficient (serum retinol (SR) concentration $<100 \mu \mathrm{g} / \mathrm{l}$ ) and $27.9 \%$ were anaemic ( $\mathrm{Hb}$ concentration $<110 \mathrm{~g} / \mathrm{l})^{(1)}$. The reported prevalences were reason for concern, mostly because it seemed that no improvement in vitamin $\mathrm{A}$ and Fe status had been achieved since the national survey of 1994 , where $3 \cdot 3 \%$ of children were vitamin A deficient and $21 \cdot 4 \%$ anaemic $^{(2)}$.

Micronutrients such as Fe, Zn, I and vitamin A play important roles in cognitive development and function ${ }^{(3-5)}$. Because brain development, especially the frontal lobe, continues throughout childhood, deficiencies of micronutrients and macronutrients during childhood are likely to influence cognitive function ${ }^{(6)}$. Nutrients do not function in isolation,

Abbreviations: BAZ, BMI-for-age $z$-scores; BeForMi, Beverage Fortified with Micronutrients; CNS, no micronutrients (control beverage) with a non-nutritive sweetener; CRP, C-reactive protein; CS, no micronutrients (control beverage) with sugar; HAZ, height-for-age $z$-scores; HVLT, Hopkins Verbal Learning Test; ID, iron deficiency; IDA, iron-deficiency anaemia; MNS, micronutrients with sugar; MNNS, micronutrients with a non-nutritive sweetener; KABC-II, Kaufman Assessment Battery for Children II; SF, serum ferritin; SR, serum retinol; TfR, transferrin receptor; WAZ, weight-for-age $z$-Scores; ZnPP, zinc protoporphyrin. 
and a diet that is deficient in one micronutrient is also likely to be deficient in others ${ }^{(7)}$. This underlines the importance of investigating the effects of multi-micronutrient supplementation on cognitive function, particularly in populations that are likely to suffer from multiple deficiencies.

Fortification of food with micronutrients is increasingly considered as an alternative strategy to micronutrient supplementation. A micronutrient-fortified beverage that forms part of a comprehensive integrated nutritional fortification programme has been reported to be of possible benefit in populations at risk of micronutrient deficiencies ${ }^{(8)}$. In 1994, the National School Nutrition Programme (NSNP) was introduced in South Africa ${ }^{(9)}$ without targeting micronutrient deficiencies per se. The NSNP forms a highly suitable intervention channel for providing a large number of children with micronutrient-fortified foods.

A number of studies have reported on the adverse effects of missing breakfast on memory ${ }^{(10-12)}$. Studies have shown the positive effects of breakfast consumption on academic performance in schoolchildren ${ }^{(13)}$. Similarly, several studies have demonstrated that the provision of glucose, which is the primary breakdown product of carbohydrate and the major fuel of the brain, enhances cognitive performance, particularly in tasks that require aspects of memory ${ }^{(7,14-17)}$. However, the majority of these studies have investigated the effects of acute intervention, while data on the effects of long-term administration of carbohydrate on cognitive performance are lacking. Since there is sound evidence for the short-term effects of glucose and other carbohydrates on mental performance, the long-term administration of sugar (sucrose), which is a disaccharide composed of the monosaccharides glucose and fructose, may have a cumulative beneficial effect on cognitive functioning, particularly in schoolchildren with inadequate habitual energy intake.

The Beverage Fortified with Micronutrients (BeForMi) study was conducted in view of the potential adverse effects of poor micronutrient status and low habitual energy intake on cognitive performance in South African schoolchildren. Furthermore, the provision of both micronutrients and sugar may enhance growth ${ }^{(8)}$. The provision of micronutrients and sugar in combination may be more beneficial than the administration of these nutrients alone. Therefore, the BeForMi study was a randomised, controlled intervention with the aim of investigating the effects of a multi-micronutrientfortified beverage, with or without sugar, on growth and cognitive function in South African primary schoolchildren.

\section{Experimental methods}

\section{Study population}

The BeForMi study was conducted in primary schoolchildren between the ages of 6 and 11 years in a peri-urban settlement in the North West province in South Africa. The study was conducted in three pre-selected primary schools chosen by the Department of Education. Learners at all three schools were provided a single daily meal, sponsored by the National School Nutrition Programme. The study started in January
2010 and ended in November 2010. The inclusion criteria were as follows: (1) no health condition that would make cognitive testing impractical (e.g. dyslexia and hearing difficulties); (2) 6-10 years old by January 2010; (3) no use of medication or supplements that could affect nutritional status. In December 2009, study information and information on the screening process were provided to the parents of the learners in grades 1 to 3 . Consent forms were compiled in the most commonly spoken languages of the catchment area of the schools. The study was registered with the North West Department of Health (NWEP 04/2010) and permission was granted by the Department of Education as well as by the School Governing Body of each school. The present study was conducted according to the guidelines laid down in the Declaration of Helsinki, and all procedures involving human subjects were approved by the Research and Ethics Committee of the North-West University (NWU-0006509-A1). Written informed consent was obtained from all parents or guardians and oral assent from the children.

Power calculations were based on a pilot study involving similar cognitive tests and preschool children in a similar socio-economic setting ${ }^{(18)}$. Point-of-use fortification of food with micronutrients in the pilot study resulted in a decrease in the three mental processing index scores of the Kaufman Assessment Battery for Children II (KABC-II) of medium effect size $(d=0 \cdot 4)$. The power calculations indicated that 100 learners per treatment group would be sufficient to provide $80 \%$ power at a 0.05 significance level and allow for a $10 \%$ dropout rate. In total, 556 children participated in the baseline screening. After screening, the 414 children with the highest serum transferrin receptor (TfR) values and thereafter the highest zinc protoporphyrin (ZnPP) values were enrolled into the study in order to include those children with the poorest Fe status (Fig. 1).

\section{Study design}

In the present double-blind, randomised, controlled intervention study, the 414 pre-selected children were randomly allocated to one of four treatment groups. The four different formulations of the beverages were as follows: (1) micronutrients with sugar (MNS); (2) no micronutrients (control beverage) with sugar (CS); (3) micronutrients with a nonnutritive sweetener (MNNS); (4) no micronutrients (control beverage) with a non-nutritive sweetener (CNS) (Table 1). The non-nutritive sweetener sucralose was used in the beverages without sugar, and the colourant Yellow Sunset E110 was used to give a similar colour to the micronutrient-containing beverages that had $\beta$-carotene. All the beverage formulations were, therefore, identical in colour and taste. The participants, investigators and school assistants were blinded to treatment assignments. Randomisation of the four beverage formulations was done within schools, classrooms and sex.

Distribution of the beverages started in March 2010 and continued until 30 November 2010. Children were de-wormed at the baseline with $200 \mathrm{mg}$ ( $100 \mathrm{mg}$ twice daily) of mebendazole for three consecutive days. 


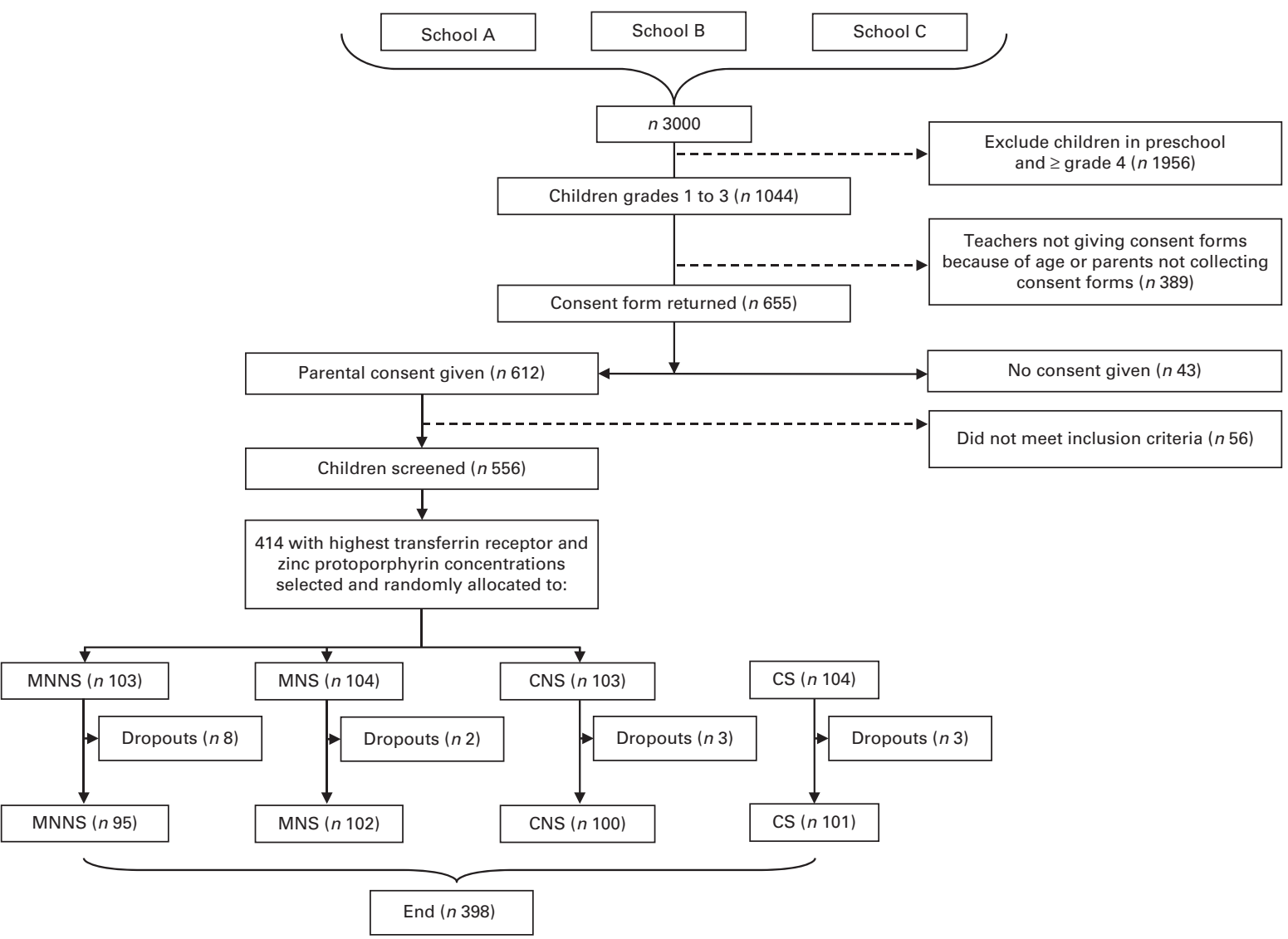

Fig. 1. Participant flow chart. MNNS, beverage containing micronutrients with a non-nutritive sweetener; MNS, beverage containing micronutrients with sugar; CNS, control beverage with a non-nutritive sweetener; CS, control beverage with sugar.

\section{Intervention}

The respective BeForMi formulations are summarised in Table 1 . Beverages $(200 \mathrm{ml}$ per child per d) were consumed during school hours, before the school meal, from Monday to Friday. The total beverages needed for the day were mixed according to calculations, based on the number of children present each day (one sachet for 10 litres of beverage). Each day, the different beverages were freshly prepared.

The different beverage formulations were colour coded, and children who participated in the study received identity cards with their respective colour codes. A school assistant was appointed to take care of a specific colour-coded beverage at each of the three schools for the duration of the study. The responsible school assistant served his/her learners with the correct BeForMi beverage in colour-coded cups. Each child had to finish his/her beverage in front of the school assistant. Adherence was monitored by the use of illness and adherence forms that were filled in on a daily basis.

When a child was absent, the school assistant followed up on the child the next day and the reason for absence was recorded. Visits by the BeForMi study team to the schools were made at least twice weekly, and the illness and adherence forms were collected at the end of each month. These forms were screened monthly to ensure that all the information needed was provided. The school assistants were instructed to report problems immediately, so that they could be addressed effectively.

The intervention started in March and continued until November 2010. Children did not receive beverages over weekends and school holidays. The schools closed for public holidays in March/April for 2 weeks, in June/July for 5 weeks and in September for 1 week. In addition to the public holidays, fourteen school days were lost when teachers participated in a national strike. The BeForMi beverages were provided for $141 \mathrm{~d}$ over a period of 8.5 months.

\section{Biochemical indicators}

A venous blood sample of $10 \mathrm{ml}$ was collected at the baseline and endpoint from each child. This included a $6 \mathrm{ml}$ sample in a trace-element-free tube and a $4 \mathrm{ml}$ sample in an EDTAcoated tube. Blood was transported on ice to the laboratory at the Centre of Excellence for Nutrition at the North-West University directly after the blood was drawn. $\mathrm{Hb}$ concentration was determined from whole blood and $\mathrm{ZnPP}$ concentration from washed erythrocytes. TfR, serum ferritin (SF) and C-reactive protein (CRP) concentrations were determined from the serum. All serum samples were stored at $-80^{\circ} \mathrm{C}$ until analysis and analysed after the intervention.

$\mathrm{Hb}$ concentration was measured with an AcT 5Diff Cap Pierce Hematology Analyzer (Beckman Coulter) together 
Table 1. Nutritional composition of the intervention products per $200 \mathrm{ml}$ serving

\begin{tabular}{|c|c|c|c|c|c|}
\hline Ingredients & MNS & CS & MNNS & CNS & $\begin{array}{l}\% \text { RDA for beverages containing } \\
\text { micronutrients }(9-13 \text { years })\end{array}$ \\
\hline Energy $(\mathrm{kJ})^{\star}$ & 340 & 340 & $<14$ & $<14$ & \\
\hline Protein $(g)$ & 0 & 0 & 0 & 0 & \\
\hline Carbohydrate from sugar (sucrose) (g) & $20 \cdot 6$ & $20 \cdot 6$ & 0 & 0 & \\
\hline Sucralose $(\mathrm{mg})$ & 0 & 0 & 25 & 25 & \\
\hline Fat & Trace & Trace & Trace & Trace & \\
\hline Dietary fibre & 0 & 0 & 0 & 0 & \\
\hline $\mathrm{Na}$ & Trace & Trace & Trace & Trace & \\
\hline Vitamin A ( $\mu \mathrm{g} R E)$ ( $\beta$-carotene) & 400 & & 400 & & 66 \\
\hline Vitamin $\mathrm{E}(\mathrm{mg})$ & 7.5 & & 7.5 & & 68 \\
\hline Vitamin C (mg) & 60 & & 60 & & 133 \\
\hline Vitamin $B_{2}(\mathrm{mg})$ & 0.4 & & 0.4 & & \\
\hline Nicotinamide (mg) & $2 \cdot 7$ & & $2 \cdot 7$ & & 44 \\
\hline Vitamin $\mathrm{B}_{6}(\mathrm{mg})$ & 0.5 & & 0.5 & & 50 \\
\hline Folic acid ( $\mu \mathrm{g})$ & 140 & & 140 & & 46 \\
\hline Vitamin $B_{12}(\mu \mathrm{g})$ & 1.0 & & 1.0 & & 55 \\
\hline $\mathrm{Ca}(\mathrm{mg})$ & 120 & & 120 & & $9+$ \\
\hline $\mathrm{Fe}$ (mg) (ferrous chloride glycine) & $7 \cdot 0$ & & $7 \cdot 0$ & & 87 \\
\hline $\mathrm{Zn}(\mathrm{mg})$ & 3.75 & & 3.75 & & 46 \\
\hline$I(\mu g)$ & 60 & & 60 & & 50 \\
\hline
\end{tabular}

MNS, beverage containing micronutrients with sugar; CS, control beverage with sugar; MNNS, beverage containing micronutrients with a non-nutritive sweetener; CNS, control beverage with a non-nutritive sweetener; $\mathrm{RE}$, retinol equivalents.

* Non-nutritive sweetener (sucralose) used for the CNS and MNNS groups.

†Adequate intake.

with the three-level controls provided by the manufacturer. $\mathrm{Hb}$ and $\mathrm{ZnPP}$ measurements were done on the same day the blood samples were collected. ZnPP concentration was measured using washed erythrocytes with a haematofluorometer (Aviv Biomedical) with the three-level controls provided by the manufacturer. SF concentration was measured using the WHO international standard (NIBSC code: 94/572). TfR and SF concentrations were measured using ELISA (Ramco Laboratories, Inc.). CRP concentration was measured using an immunoturbidimetric test (Human Biochemical and Diagnostic Laboratories).

Serum Zn concentration was determined by flame atomic absorption spectrometry (Thermo Elemental, S2 AAS SOLAAR AA series; Thermo Fisher Scientific, Inc.). SR concentration was determined by a reversed-phase HPLC method based on the method described by Catignani \& Bieri ${ }^{(19)}$, using tocopherol acetate as the internal standard. Fe deficiency (ID) was defined as $\mathrm{ZnPP}$ concentration $\leq 70 \mu \mathrm{mol} / \mathrm{mol}$ haem (Aviv Biomedical), TfR concentration $>8.3 \mathrm{mg} / \mathrm{l}$ (Ramco Laboratories, Inc.) or SF concentration $<15 \mu \mathrm{g} / 1$ (3rd WHO International Standard, 1996, 94/572). Anaemia was defined as a $\mathrm{Hb}$ concentration $<115 \mathrm{~g} / \mathrm{l}^{(20)}$. CRP concentration $>5 \mathrm{mg} / \mathrm{l}$ indicated low-grade inflammation ${ }^{(20)}$. SF values of children with a CRP concentration $>5 \mathrm{mg} / \mathrm{l}$ were adjusted using a correction factor of 0.65 as suggested by Thurnham et al. ${ }^{(21)}$.

SR concentrations $<200 \mu \mathrm{g} / \mathrm{l}(0.7 \mu \mathrm{mol} / \mathrm{l})$ and $<100 \mu \mathrm{g} / \mathrm{l}$ $(0.35 \mu \mathrm{mol} / \mathrm{l})$ were indicative of low vitamin A status and vitamin A deficiency, respectively ${ }^{(22)}$. SR concentrations of children with CRP concentrations $>5$ and $<10 \mathrm{mg} / \mathrm{l}$ and with a CRP concentration $\geq 10 \mathrm{mg} / 1$ were adjusted by adding $45.8 \mu \mathrm{g} / \mathrm{l}(0.16 \mu \mathrm{mol} / \mathrm{l})$ and $91.5 \mu \mathrm{g} / \mathrm{l}(0.32 \mu \mathrm{mol} / \mathrm{l})$, respectively, as suggested by Kongsbak et al. ${ }^{(23)}$. A serum $\mathrm{Zn}$ concentration $<650 \mu \mathrm{g} / 1$ (9.9 $\mu \mathrm{mol} / \mathrm{l})$ indicated inadequate $\mathrm{Zn}$ status $^{(24)}$.

\section{Cognitive test}

Cognitive performance was assessed at the baseline and endpoint using the KABC-II ${ }^{(25)}$. The tests included in this battery were devised in the United States and are based on the neuropsychological theories of Luria. The construct validity of the KABC-II has been demonstrated in African children in Uganda ${ }^{(26)}$ The KABC-II tests are further recommended for children from bilingual backgrounds, where cultural background could affect knowledge acquisition and verbal development. For the BeForMi study, the selected KABC-II subtests were those that involved activities that children in this population set-up would be familiar with to avoid bias due to lack of cultural familiarity. The constructs that these subtests are based on are also those that have been shown to have sensitivity to changes in nutritional status of African children $^{(27)}$. Selected cognitive tests were used to assess different cognitive functions. 'Story completion' and 'Rover' were used to measure planning ability. Rover also measures simultaneous processing, along with 'Triangles'. 'Hand movements', 'Word order' and 'Number recall' were used to measure sequential processing and 'Atlantis' was used to measure learning ability $^{(28)}$. In addition to the KABC-II, an adapted and modified version of the Hopkins Verbal Learning Test $\left(\right.$ HVLT) ${ }^{(29)}$ was used to test short-term memory by recall and ability to discriminate among words in a familiar setting. The HVLT was modified to include nine words each for related and unrelated words instead of the usual six in order to avoid saturation on the recall exercises.

A team of eight locally trained cognitive assessors conducted the testing. All the cognitive assessors were blinded to treatment group allocation. The cognitive assessors underwent intensive training by a trained experienced assessor and a psychologist oversaw the process (J. D. K.). The week 
before baseline and endpoint cognitive measurements were taken, training was repeated. Children were assessed during morning school hours on the school premises in semi-private areas. The tests were administered to children using the language medium of education of the particular school.

The scores from the KABC-II tests were adjusted for age by using the KABC-II Assist software package (NCS Pearson, Inc.). Inter-tester reliability was determined using a testretest process. This process included children who used the same language medium of education from two schools that did not form part of the study. In addition, adapted versions of the Cronbach $\alpha$ equation according to Foxcroft $\&$ Roodt ${ }^{(30)}$ were used to determine intra-tester reliability coefficients based on the first eight children assessed by each assessor. Cronbach $\alpha$ for inter-tester reliability for cognitive assessors was 0.76 (95\% CI $0.61,0.87)$. The intra-tester reliabilities for the eight assessors ranged from 0.67 to 0.91 (mean $=0.80$ ).

\section{Anthropometry}

All anthropometric measurements were taken according to the International Standards for Anthropometric Assessment of the International Society for the Advancement of Kinanthropometry. Body weight of children wearing minimum clothing without shoes was measured on the Seca Robusta 813 digital scale (Seca). Body weight was recorded to the nearest $100 \mathrm{~g}$. For height measurements, children stood upright without shoes with the head in the Frankfort plane. Height measurements were taken using a calibrated stadiometer (Seca) measured to the nearest $0 \cdot 1 \mathrm{~cm}$.

The 2007 WHO references (WHO AnthroPlus, version 1.0.2 software; http://www.who.int/childgrowth/software/en) were used to calculate age- and sex-specific weight-for-age $z$-scores (WAZ), BMI-for-age $z$-scores (BAZ) and heightfor-age $z$-scores (HAZ). WAZ are only available in the software for children aged $<10$ years. A $z$-score $<-2$ indicated underweight (WAZ $<-2$ ), wasting (BAZ $<-2$ ) and stunting (HAZ $<-2)$.

\section{Dietary vitamin A, zinc, iron and energy intakes and sociodemographic questionnaire}

Trained school assistants conducted three $24 \mathrm{~h}$ recalls at least 1 week apart on different days of the week. Among the three $24 \mathrm{~h}$ recalls, two recalls per child were conducted for weekdays and one recall was conducted for a weekend day. Dietary data were analysed with the Food Finder computer program (Medical Research Council, 2003). The $24 \mathrm{~h}$ dietary recalls and an existing sociodemographic questionnaire adapted for the present study were administered to the parents/caregivers in their language of choice.

\section{Statistical analyses}

Statistical analyses were performed using IBM SPSS Statistics (version 19; IBM Corporation). Descriptive statistics were calculated to present means, standard deviations and frequencies of variables. Differences between the treatment groups at the baseline were investigated using ANOVA. Estimated interven- tion effects of micronutrient fortification (micronutrients $v$. control) and sugar (sugar $v$. non-nutritive sweetener) and the interaction between micronutrients and sugar were analysed using a two-factor ANCOVA on endpoint measurements, controlling for the respective baseline values, sex and age. In addition, for cognitive tests, the years a child attended crèche, the income of the head of the household and the education level of the mother were added as covariates. If one of these sociodemographic factors was a significant predictor of endpoint cognitive test scores, it was added as a covariate in the specific test or removed from the analysis if not significant.

OR for being deficient at the endpoint (anaemia, Fe- and Zn-deficient and low vitamin A status) with treatment (micronutrients and/or sugar) were examined using binary logistic regression analyses, adjusting for age, sex, respective baseline deficiency prevalence and adding a micronutrient $x$ sugar interaction term. McNemar's test was used to determine whether the prevalence of deficiencies changed significantly from the baseline to endpoint within the groups. For dietary intake of micronutrients and energy, dependent $t$ tests were used to compare changes in means over time within the groups and independent $t$ tests were used to compare means between the groups. Statistically significant results were those with $P$ values $<0.05$.

\section{Results}

Subjects

Of the 556 children screened, 6.9\% were anaemic (Hb concentration $<115 \mathrm{~g} / \mathrm{l}), 27 \cdot 1 \%$ were ID based on SF concentration $(<15 \mu \mathrm{g} / \mathrm{l})$ and $2 \cdot 7 \%$ had Fe-deficiency anaemia (IDA) (Hb concentration $<115 \mathrm{~g} / \mathrm{l}$ and SF concentration $<15 \mu \mathrm{g} / \mathrm{l}$ ). A total of 414 children were enrolled into the study $(52 \cdot 2 \%$ boys) and 398 completed the study (Fig. 1). All the children who dropped out from the study did so as a result of changing schools ( $n$ 16). The majority $(37 \cdot 7 \%, n 156)$ of the children came from households with four to six persons living in the same household. Nearly $60 \%$ of the heads of the households reported an income of less than or equal to R2000 $( \pm 240$ United States dollars (USD)) per month ( $n$ 242). Among the mothers of children, $15 \%$ ( $n$ 61) had primary school education and $43 \%$ ( $n$ 177) had secondary school education. Crèche was attended by $58 \%$ ( $n$ 240) of children before primary school. Table 2 presents the baseline characteristics of the children by treatment group. There were no relevant differences between the treatment groups in any baseline characteristics.

\section{Intervention adherence}

The adherence of children to beverage intake was high. Based on the $141 \mathrm{~d}$ that the beverages were provided, a 95\% adherence rate was achieved. Therefore, none of the children who completed the study was excluded from the statistical analyses because of poor adherence.

\section{Dietary vitamin A, zinc, iron and energy intakes}

Complete dietary data of three $24 \mathrm{~h}$ questionnaires per study child were obtained from $90 \%$ of the study children. 
Table 2. Characteristics of the children at the baseline by treatment group

\begin{tabular}{|c|c|c|c|c|}
\hline & \multicolumn{4}{|c|}{ Treatment groups } \\
\hline & \multicolumn{2}{|c|}{ Control beverages } & \multicolumn{2}{|c|}{$\begin{array}{l}\text { Beverages with } \\
\text { micronutrients }\end{array}$} \\
\hline & $\begin{array}{l}\text { CNS } \\
(n 102)\end{array}$ & $\begin{array}{c}\text { CS } \\
(n \text { 104) }\end{array}$ & $\begin{array}{l}\text { MNNS } \\
(n 100)\end{array}$ & $\begin{array}{l}\text { MNS } \\
(n \text { 102) }\end{array}$ \\
\hline Boys (\%) & $48 \cdot 0$ & 50 & 50 & $57 \cdot 8$ \\
\hline \multicolumn{5}{|l|}{ Age (years) } \\
\hline Mean & $8 \cdot 2$ & $8 \cdot 1$ & $7 \cdot 9$ & $8 \cdot 3$ \\
\hline SD & 0.8 & 0.9 & 1.4 & 0.9 \\
\hline \multicolumn{5}{|l|}{ Anthropometric indices (\%) } \\
\hline Stunted $(\mathrm{HAZ}<-2)$ & 12 & 14.7 & 8 & $14 \cdot 7$ \\
\hline Wasted $(B A Z<-2)$ & $7 \cdot 1$ & $10 \cdot 8$ & 6 & $10 \cdot 9$ \\
\hline Underweight $(W A Z<-2)$ & 13.4 & 13.4 & 14.4 & $16 \cdot 5$ \\
\hline \multicolumn{5}{|l|}{ Deficiencies (\%) } \\
\hline Anaemia $(\mathrm{Hb}$ concentration $<115 \mathrm{~g} / \mathrm{l})$ & $8 \cdot 8$ & $5 \cdot 8$ & $8 \cdot 1$ & $5 \cdot 8$ \\
\hline Low Fe stores (serum ferritin concentration $<15 \mu \mathrm{g} / \mathrm{l}^{\star}$ & 22.4 & 33.3 & $32 \cdot 0$ & $26 \cdot 5$ \\
\hline Fe deficiency based on transferrin receptors (transferrin receptor concentration $>8.3 \mathrm{mg} / \mathrm{l}$ ) & $7 \cdot 8$ & 4.9 & $10 \cdot 0$ & $7 \cdot 8$ \\
\hline Fe deficiency based on zinc protoporphyrin (zinc protoporphyrin concentration $>70 \mu \mathrm{mol} / \mathrm{mol}$ haem) & 24.5 & $18 \cdot 4$ & $29 \cdot 0$ & $18 \cdot 6$ \\
\hline Fe-deficiency anaemia $(\mathrm{Hb}$ concentration $<115 \mathrm{~g} / \mathrm{l}$ and serum ferritin concentration $<15 \mu \mathrm{g} / \mathrm{l})$ & $2 \cdot 0$ & 1.9 & $6 \cdot 1$ & 2.9 \\
\hline Zn deficiency (serum $\mathrm{Zn}$ concentration $<650 \mu \mathrm{g} / \mathrm{l}$ ) & $9 \cdot 8$ & $19 \cdot 8$ & 8.0 & 10.7 \\
\hline Low vitamin A status (serum retinol concentration $<200 \mu \mathrm{g} / \mathrm{l}) \dagger$ & 3.0 & $4 \cdot 0$ & 3.0 & 3.9 \\
\hline Vitamin A deficiency (serum retinol concentration $<100 \mu \mathrm{g} / \mathrm{l}$ ) & 0 & 0 & 0 & 0 \\
\hline \multicolumn{5}{|l|}{ Acute-phase protein (\%) } \\
\hline C-reactive protein $(>5 \mathrm{mg} / \mathrm{l})$ & $26 \cdot 5$ & $20 \cdot 4$ & $25 \cdot 0$ & $32 \cdot 4$ \\
\hline
\end{tabular}

Dietary vitamin A, Zn and Fe intakes, with and without the beverages, as calculated from the $24 \mathrm{~h}$ recalls are reported in Table 3. As expected, the children who received the micronutrient-fortified beverages (MNS + MNNS) had significantly higher mean $\mathrm{Fe}$, vitamin $\mathrm{A}$ and $\mathrm{Zn}$ intakes (intervention beverage included) than those who received the beverages without added micronutrients (CS $+\mathrm{CNS}$ ). Furthermore, the micronutrient-fortified beverages significantly increased the daily mean dietary intakes of vitamin A, Zn and Fe. Mean dietary intakes from food alone were above the estimated average requirements for $\mathrm{Fe}$ and $\mathrm{Zn}$ or the RDA for vitamin $\mathrm{A}^{(31)}$ in all the treatment groups without the additional micronutrients provided by the BeForMi beverages. The 1989 RDA for vitamin A was used, because the unit of measurement is $\mu \mathrm{g}$ retinol equivalents, which is the same unit in which the vitamin A intake of the children was measured ${ }^{(32)}$.

Based on the results from the $24 \mathrm{~h}$ recall questionnaires, the daily habitual energy intakes were 5885.2 (SD 1719.0) kJ in the MNNS group, $6427 \cdot 2$ (SD 1919.5) $\mathrm{kJ}$ in the MNS group, $6910 \cdot 6$ (SD $1769 \cdot 0) \mathrm{kJ}$ in the CS group and 7108.2 (SD 1912.5) $\mathrm{kJ}$ in the CNS group. The MNNS group had a significantly lower habitual energy intake than the CS $(P=0.001)$ and the CNS $(P<0.001)$ groups, while the MNS group did not differ from any of the other groups $(P>0.05)$. The daily energy intake in the children who consumed the beverages with sugar (CS + MNS) was significantly higher than that in those consuming the beverages with a non-nutritive sweetener (CNS + MNNS) (7013.51 (sD 1859.9) v. 6594.3 (sD 2198.8) kJ). The daily energy intakes including the additional energy from the beverages were 6065.9 (SD 2347.3) kJ in the MNNS group, 6776.0 (SD 1914.8) kJ in the MNS group, 7268.6 (SD 1768.9) in the CS group and $7120 \cdot 2$ (SD 1912.5) $\mathrm{kJ}$ in the CNS group. The daily energy intakes including the additional energy from the beverages remained significantly lower in the MNNS group than in the CNS $(P=0.002)$ and CS $(P<0.001)$ groups, and the MNS group remained not being different from the other groups $(P>0.05)$. Irrespective of the beverage formulation (with and without sugar), the mean energy intake in the study children was below the estimated energy requirements of $9572 \mathrm{~kJ}$ for boys and $8698 \mathrm{~kJ}$ for girls ${ }^{(31)}$.

\section{Biochemical indicators}

Baseline and endpoint concentrations of serum vitamin A, serum $\mathrm{Zn}, \mathrm{Hb}$ and $\mathrm{Fe}$ status indicators are presented in Table 4 . There were no relevant differences at the baseline for any of the reported variables. In order to determine the treatment effects of micronutrient fortification (micronutrient $v$. control) and sugar (sugar $v$. non-nutritive sweetener) and potential interaction effects of micronutrient $\times$ sugar on endpoint biochemical indicators, a two-factor ANCOVA was conducted, controlling for age, sex and respective baseline measurements. There were significant micronutrient effects on the Fe status indicators SF $(P=0.003)$ and $\mathrm{ZnPP}$ ( $P=0.034)$ for better Fe status at the endpoint. Furthermore, there was a significant effect of micronutrient fortification on a higher $\mathrm{Hb}$ concentration at the endpoint $(P=0.007)$. 
In binary logistic regression, controlling for age, sex and respective baseline ID status, micronutrient fortification significantly decreased the OR for being ID (based on SF) at the endpoint (OR 0.20; 95\% CI 0.07, 0.53). The prevalence of ID significantly decreased from $29 \cdot 2$ to $5 \cdot 5 \%$ in children who received the micronutrient-fortified beverages, while it remained unchanged $(27.9 \%$ at the baseline to $20.9 \%$ at the endpoint) in those who received the beverages without micronutrients. Micronutrient fortification did not significantly lower the risk for being ID at the endpoint based on $\mathrm{ZnPP}$ and TfR concentrations $(P>0.05)$ and for being anaemic at the endpoint $(P>0 \cdot 05)$.

The prevalence of Zn deficiency (serum Zn concentration $<650 \mu \mathrm{g} / \mathrm{l}$ ) improved significantly from the baseline to endpoint in both the children who received the beverages fortified with micronutrients ( 9.4 to $2.0 \%)(P=0.007)$ and the children who received the beverages without micronutrients (14.4 to $2.6 \%)(P<0.001)$. There was no significant effect of micronutrient fortification on vitamin A status.

\section{Cognitive performance}

Intervention effects of micronutrient fortification and sugar, as well as possible micronutrient $\times$ sugar interactions, were analysed using a two-factor ANCOVA, adding age, sex and respective baseline cognitive test score as covariates (Table 5). The number of years a child spent in a crèche, the education level of the mother and the income of the head of the household were initially included as covariates. However, of these sociodemographic variables, the number of years a child spent in a crèche was the only variable that significantly affected scores in the Triangles and Story Completion tests and was, therefore, added as a covariate in the analysis of these variables. A significant effect of micronutrient fortification $(P=0.025)$ and sugar $(P=0.036)$ for higher endpoint scores was found in the Atlantis test (Fig. 2(a)). There was also a significant micronutrient $x$ sugar interaction, indicating that micronutrients or sugar provided alone had a beneficial effect on the Atlantis scores, but when given in combination, this beneficial effect was attenuated. In the Rover test, there was a significant effect of sugar on higher endpoint scores $(P=0.027)$, as well as a significant micronutrient $\times$ sugar interaction (Fig. 2(c)), indicating again that sugar alone had a beneficial effect, but when given in combination, this effect was attenuated. A significant attenuating micronutrient $\times$ sugar interaction was also found in the Number recall test (Fig. 2(b)).

In the HVLT, sugar increased the number of words recalled at Recall $3(P=0.020)$ at the endpoint, while there was a trend towards an increasing effect of sugar on the number of words recalled at Recall $2(P=0 \cdot 076)$. Consequently, there was a significant increasing effect of sugar on the mean words recalled across Recalls 1 to $3(P=0 \cdot 027)$. In contrast, there was an increasing effect of micronutrients on the Discrimination Index scores at the endpoint $(P=0.048)$ and a trend towards a micronutrient $\times$ sugar interaction $(P=0.069)$. Micronutrients alone increased the Discrimination Index scores, while this increase was attenuated when micronutrients were provided in combination with sugar (Fig. 2(d)). 
Table 4. Effect of a beverage with and without micronutrients by treatment group on the indicators of iron, zinc and vitamin A status (Mean values and standard deviations; B values and $95 \%$ confidence intervals)

\begin{tabular}{|c|c|c|c|c|c|c|c|c|c|c|c|c|c|}
\hline & \multicolumn{8}{|c|}{ Treatment groups } & \multicolumn{4}{|c|}{ Estimated intervention effect ${ }^{*}$} & \multirow{3}{*}{$\frac{\text { Micronutrient } \times \text { sugar }}{P}$} \\
\hline & \multicolumn{2}{|c|}{ MNS ( $n$ 101) } & \multicolumn{2}{|c|}{ MNNS ( $n$ 95) } & \multicolumn{2}{|c|}{$\operatorname{CS}(n 98)$} & \multicolumn{2}{|c|}{ CNS ( $n$ 92) } & \multicolumn{2}{|c|}{ Micronutrient } & \multicolumn{2}{|c|}{ Sugar } & \\
\hline & Mean & SD & Mean & SD & Mean & SD & Mean & SD & B & $95 \% \mathrm{Cl}$ & B & $95 \% \mathrm{Cl}$ & \\
\hline \multicolumn{14}{|c|}{ Blood Hb (g/l) } \\
\hline Baseline & 127 & 9 & 125 & 11 & 127 & 8 & 127 & 10 & $3 \cdot 1 \dagger$ & $0.9,5 \cdot 3$ & 0.4 & $-0.19,0.26$ & 0.42 \\
\hline Endpoint & 130 & 9 & 129 & 10 & 127 & 9 & 127 & 11 & & & & & \\
\hline \multicolumn{14}{|c|}{ Serum ferritin $(\mu \mathrm{g} / \mathrm{l}) \ddagger$} \\
\hline Baseline & 27.5 & $17 \cdot 1$ & $25 \cdot 5$ & 17.7 & $27 \cdot 9$ & 21.4 & $28 \cdot 1$ & $18 \cdot 4$ & $8.79 \S$ & $3.03,14.55$ & $1 \cdot 24$ & $-4.58,7.05$ & 0.55 \\
\hline Endpoint & 43.2 & $25 \cdot 3$ & 37.9 & 23.8 & 31.5 & $17 \cdot 3$ & 29.5 & $20 \cdot 1$ & & & & & \\
\hline \multicolumn{14}{|c|}{ Zinc protoporphyrin ( $\mu \mathrm{mol} / \mathrm{mol}$ haem) } \\
\hline Baseline & 59.4 & 23.9 & 63.4 & $26 \cdot 1$ & $57 \cdot 6$ & $16 \cdot 8$ & 61.4 & $22 \cdot 5$ & $-4 \cdot 10 \|$ & $-7.89,0.32$ & $2 \cdot 25$ & $-1.52,6.02$ & 0.54 \\
\hline Endpoint & $65 \cdot 8$ & $24 \cdot 6$ & 65.5 & 21.8 & $66 \cdot 6$ & $20 \cdot 2$ & 68.5 & $26 \cdot 8$ & & & & & \\
\hline \multicolumn{14}{|c|}{ Serum transferrin receptor $(\mu \mathrm{g} / \mathrm{l})$} \\
\hline Baseline & $6 \cdot 0$ & $1 \cdot 3$ & $6 \cdot 3$ & 1.9 & $6 \cdot 0$ & $1 \cdot 1$ & $6 \cdot 3$ & $2 \cdot 1$ & -0.27 & $-0.64,0.10$ & 0.03 & $-0.34,0.40$ & 0.84 \\
\hline Endpoint & $6 \cdot 7$ & $1 \cdot 2$ & $6 \cdot 8$ & 1.5 & 7.0 & 1.4 & $7 \cdot 1$ & $2 \cdot 1$ & & & & & \\
\hline \multicolumn{14}{|c|}{ Serum Zn ( $\mu \mathrm{g} / \mathrm{l})$} \\
\hline Baseline & 80.5 & $13 \cdot 8$ & $80 \cdot 4$ & $12 \cdot 3$ & 77.7 & $15 \cdot 1$ & $81 \cdot 6$ & $12 \cdot 9$ & -1.41 & $-5 \cdot 25,2.44$ & $-2 \cdot 80$ & $-6.64,1.04$ & 0.18 \\
\hline Endpoint & 87.5 & $13 \cdot 0$ & 88.3 & $12 \cdot 3$ & $85 \cdot 0$ & $12 \cdot 0$ & $86 \cdot 5$ & $12 \cdot 4$ & & & & & \\
\hline \multicolumn{14}{|c|}{ Serum retinol $(\mu \mathrm{g} / \mathrm{l})$ q } \\
\hline Baseline & 302 & 64 & 300 & 61 & 284 & 53 & 300 & 60 & $4 \cdot 8$ & $-11 \cdot 8,21 \cdot 4$ & -3.9 & $-20 \cdot 6,12 \cdot 9$ & 0.916 \\
\hline Endpoint & 34.4 & $7 \cdot 6$ & $34 \cdot 3$ & $7 \cdot 4$ & $32 \cdot 3$ & $6 \cdot 7$ & 33.7 & $6 \cdot 6$ & & & & & \\
\hline
\end{tabular}

MNS, beverage containing micronutrients with sugar; MNNS, beverage containing micronutrients with a non-nutritive sweetener; CS, control beverage with sugar; CNS, control beverage with a non-nutritive sweetener. *Micronutrient and sugar group intervention effects as well as micronutrient $\times$ sugar interaction effects were estimated using a two-way ANCOVA comparing endpoints, adjusted for respective baseline values, age and sex. $\dagger P=0.007$.

‡ Serum ferritin values of all children with a C-reactive protein concentration $>5 \mathrm{mg} / \mathrm{l}$ (baseline MNS, $n$ 31; MNNS, $n$ 24; CS, $n$ 21; CNS, $n$ 26; endpoint MNS, $n$ 36; MNNS, $n$ 30; CS, $n$ 35; CNS, $n$ 36) were adjusted for subclinical inflammation by multiplying serum ferritin values with a correction factor of 0.65 as suggested by Thurnham et al. ${ }^{(21)}$.

$\S P=0.003$

$\| P=0.034$. Kongsbak et al. ${ }^{(23)}$. 


\section{Nes British Journal of Nutrition}

Table 5. Effect of a beverage with and without micronutrients by treatment group on cognitive test scores

(Mean values and standard deviations; B values and $95 \%$ confidence intervals)

\begin{tabular}{|c|c|c|c|c|c|c|c|c|c|c|c|c|c|}
\hline & \multicolumn{8}{|c|}{ Treatment groups } & \multicolumn{4}{|c|}{ Estimated intervention effect } & \multirow{3}{*}{$\frac{\text { Micronutrient } \times \text { sugar } \dagger}{P}$} \\
\hline & \multicolumn{2}{|c|}{ MNS ( $n$ 101) } & \multicolumn{2}{|c|}{ MNNS ( $n$ 99) } & \multicolumn{2}{|c|}{ CS (n 99) } & \multicolumn{2}{|c|}{ CNS $(n$ 100) } & \multicolumn{2}{|c|}{ Micronutrient } & \multicolumn{2}{|c|}{ Sugar } & \\
\hline & Mean & SD & Mean & SD & Mean & SD & Mean & SD & $\mathrm{B}$ & $95 \% \mathrm{Cl}$ & B & $95 \% \mathrm{Cl}$ & \\
\hline \multicolumn{14}{|c|}{$\begin{array}{l}\text { Kaufman Assessment Battery } \\
\text { for Children } \\
\text { Atlantis }\end{array}$} \\
\hline Baseline & 3.9 & 1.9 & 4.2 & $2 \cdot 4$ & 4.0 & $2 \cdot 4$ & 3.8 & $1 \cdot 8$ & 0.76 & $0 \cdot 10,1 \cdot 42 \ddagger$ & 0.71 & $0.05,1.37 \S$ & 0.011 \\
\hline Endpoint & 5.4 & 2.5 & 5.9 & $2 \cdot 9$ & 5.8 & 2.9 & $5 \cdot 0$ & 2.4 & & & & & \\
\hline \multicolumn{14}{|c|}{ Story completion } \\
\hline Baseline & 3.9 & 1.8 & 3.9 & $2 \cdot 1$ & 3.8 & $1 \cdot 8$ & 3.8 & $2 \cdot 0$ & -0.02 & $-0.57,0.53$ & 0.11 & $-0.42,0.67$ & $0.36 \|$ \\
\hline Endpoint & 3.5 & 1.9 & 3.9 & $2 \cdot 4$ & 3.9 & $2 \cdot 0$ & 3.8 & $2 \cdot 1$ & & & & & \\
\hline \multicolumn{14}{|c|}{ Number recall } \\
\hline Baseline & $6 \cdot 2$ & $2 \cdot 2$ & 6.5 & 2.5 & 6.5 & $2 \cdot 0$ & $6 \cdot 4$ & $2 \cdot 3$ & 0.24 & $-0.39,0.87$ & 0.48 & $-0.15,1 \cdot 11$ & 0.044 \\
\hline Endpoint & $6 \cdot 1$ & 3.2 & $6 \cdot 6$ & 2.5 & 6.8 & 2.4 & $6 \cdot 3$ & $2 \cdot 3$ & & & & & \\
\hline \multicolumn{14}{|l|}{ Rover } \\
\hline Baseline & $7 \cdot 1$ & 2.4 & $7 \cdot 2$ & $2 \cdot 2$ & 7.4 & $2 \cdot 3$ & $7 \cdot 3$ & $2 \cdot 1$ & 0.39 & $-0.25,1.02$ & 0.72 & $0 \cdot 08,1 \cdot 35^{\star}$ & 0.046 \\
\hline Endpoint & 7.5 & $2 \cdot 4$ & 7.8 & 2.5 & $8 \cdot 1$ & $2 \cdot 3$ & 7.3 & $2 \cdot 4$ & & & & & \\
\hline \multicolumn{14}{|l|}{ Triangles } \\
\hline Baseline & $5 \cdot 2$ & $2 \cdot 1$ & 5.5 & $2 \cdot 0$ & $5 \cdot 0$ & 1.9 & $5 \cdot 0$ & 1.9 & 0.26 & $-0.27,0.79$ & 0.21 & $-0.33,0.74$ & $0.17 \|$ \\
\hline Endpoint & $5 \cdot 0$ & 1.9 & 5.5 & $2 \cdot 2$ & 5.4 & $2 \cdot 2$ & $5 \cdot 1$ & 1.9 & & & & & \\
\hline \multicolumn{14}{|l|}{ Word order } \\
\hline Baseline & $6 \cdot 1$ & 1.5 & $6 \cdot 0$ & 1.5 & $6 \cdot 6$ & $1 \cdot 8$ & $6 \cdot 0$ & $1 \cdot 6$ & 0.03 & $-0.46,0.51$ & 0.04 & $-0.45,0.53$ & 0.56 \\
\hline Endpoint & $5 \cdot 8$ & 1.9 & $6 \cdot 0$ & 1.9 & $6 \cdot 1$ & 1.9 & 5.9 & 1.7 & & & & & \\
\hline \multicolumn{14}{|c|}{ Hand movements } \\
\hline Baseline & $6 \cdot 6$ & 2.4 & 6.8 & $2 \cdot 6$ & $6 \cdot 8$ & 2.5 & 6.5 & $2 \cdot 4$ & -0.33 & $-0.98,0.33$ & -0.34 & $-0.99,0.32$ & 0.35 \\
\hline Endpoint & 6.5 & $2 \cdot 4$ & 6.5 & $2 \cdot 4$ & 6.5 & $2 \cdot 8$ & 6.7 & $2 \cdot 8$ & & & & & \\
\hline \multicolumn{14}{|l|}{ HVLT } \\
\hline \multicolumn{14}{|l|}{ Recall 1} \\
\hline Baseline & 6.5 & $2 \cdot 6$ & 6.5 & $2 \cdot 3$ & $6 \cdot 6$ & $2 \cdot 8$ & 6.4 & $2 \cdot 5$ & 0.17 & $-0.46,0.79$ & 0.51 & $-0 \cdot 12,1 \cdot 13$ & 0.30 \\
\hline Endpoint & 7.8 & $2 \cdot 3$ & 7.7 & 2.5 & $8 \cdot 1$ & $2 \cdot 4$ & 7.5 & $2 \cdot 1$ & & & & & \\
\hline \multicolumn{14}{|l|}{ Recall 2} \\
\hline Baseline & $8 \cdot 1$ & $2 \cdot 7$ & $7 \cdot 7$ & $2 \cdot 9$ & $8 \cdot 3$ & $2 \cdot 8$ & 8.2 & $2 \cdot 9$ & 0.07 & $-0.65,0.79$ & 0.65 & $-0.07,1.37$ & 0.93 \\
\hline Endpoint & $9 \cdot 3$ & $2 \cdot 7$ & 8.5 & $2 \cdot 8$ & $9 \cdot 3$ & 3.0 & 8.6 & 2.4 & & & & & \\
\hline \multicolumn{14}{|l|}{ Recall 3} \\
\hline Baseline & 8.9 & 2.8 & 8.5 & $3 \cdot 3$ & $9 \cdot 0$ & $3 \cdot 3$ & 8.9 & $2 \cdot 9$ & 0.53 & $-0.26,1.32$ & 0.94 & $0.15,1.72 ף$ & 0.36 \\
\hline \multirow{2}{*}{\multicolumn{14}{|c|}{ Mean score recalls $1-3$}} \\
\hline & & & & & & & & & & & & & \\
\hline Baseline & 7.8 & $2 \cdot 3$ & 7.6 & $2 \cdot 4$ & 8.0 & 2.5 & 7.8 & $2 \cdot 3$ & 0.25 & $-0.34,0.84$ & 0.67 & $0.08,1.26^{\star \star}$ & 0.44 \\
\hline Endpoint & $9 \cdot 1$ & $2 \cdot 3$ & $8 \cdot 6$ & $2 \cdot 4$ & $9 \cdot 1$ & 2.5 & 8.4 & $2 \cdot 1$ & & & & & \\
\hline Recognition & & & & & & & & & & & & & \\
\hline Baseline & 14.9 & 3.3 & $16 \cdot 0$ & $2 \cdot 6$ & $16 \cdot 3$ & 1.9 & 15.9 & $2 \cdot 4$ & 0.29 & $-0.27,0.85$ & 0.19 & $-0.37,0.75$ & 0.99 \\
\hline Endpoint & $16 \cdot 0$ & $2 \cdot 0$ & $16 \cdot 1$ & $2 \cdot 3$ & $16 \cdot 0$ & $2 \cdot 1$ & $15 \cdot 7$ & $2 \cdot 0$ & & & & & \\
\hline Discriminatio & & & & & & & & & & & & & \\
\hline Baseline & $12 \cdot 7$ & $5 \cdot 0$ & $12 \cdot 2$ & $6 \cdot 1$ & $13 \cdot 2$ & $5 \cdot 2$ & $12 \cdot 8$ & 4.9 & 1.00 & $001,2 \cdot 00 \dagger \dagger$ & 0.47 & $-0.53,1.46$ & 0.062 \\
\hline Endpoint & 13.9 & 4.4 & 14.7 & $3 \cdot 7$ & 14.4 & $3 \cdot 6$ & $13 \cdot 8$ & 4.0 & & & & & \\
\hline
\end{tabular}

MNS, beverage containing micronutrients with sugar; MNNS, beverage containing micronutrients with a non-nutritive sweetener; CS, control beverage with sugar; CNS, control beverage with a non-nutritive sweetener; HVLT, Hopkins Verbal Learning Test.

† Micronutrient and sugar group intervention effects as well as micronutrient $\times$ sugar interaction effects were estimated using a two-way ANCOVA comparing endpoints, adjusted for respective baseline values, age and sex. $\neq P=0.025$.

$\ddagger P=0.025$.
$\S P=0.036$.

$\|$ Adjusted for sociodemographic variable; number of years a child attended a crèche.

१ी $P=0.020$.

†† $P=0.048$. 


\section{Growth}

Baseline and endpoint WAZ, HAZ and BAZ are reported in Table 6. There were significant effects of micronutrient fortification and sugar for lower WAZ at the endpoint (micronutrient $P=0.026$; sugar $P=0.043$ ), relative to their respective controls. Furthermore, there was a significant micronutrient $X$ sugar interaction, indicating that the provision of micronutrients or sugar alone resulted in lower endpoint WAZ, but that the provision of micronutrients in combination with sugar attenuated this lowering effect (Fig. 3).

\section{Discussion}

To our knowledge, this is the first randomised, controlled trial to investigate the effects of a micronutrient-fortified beverage, with and without sugar, on micronutrient status, growth and cognitive function using a $2 \times 2$ factorial design. The provision of a beverage fortified with micronutrients or added sugar had beneficial effects on cognition in schoolchildren, but these effects were attenuated when micronutrients and sugar were provided in combination. Furthermore, there were significant micronutrient effects on the Fe status indicators SF and ZnPP and on $\mathrm{Hb}$.

The prevalence of anaemia, ID, IDA, and vitamin A and Zn deficiencies in the study children was lower than expected. In the South African NFCS-FB in2005, the prevalence of anaemia in children aged 7-9 years for the same province was four times higher $(27 \%)^{(33)}$ than that reported in the present study. The dietary assessment done in the present study
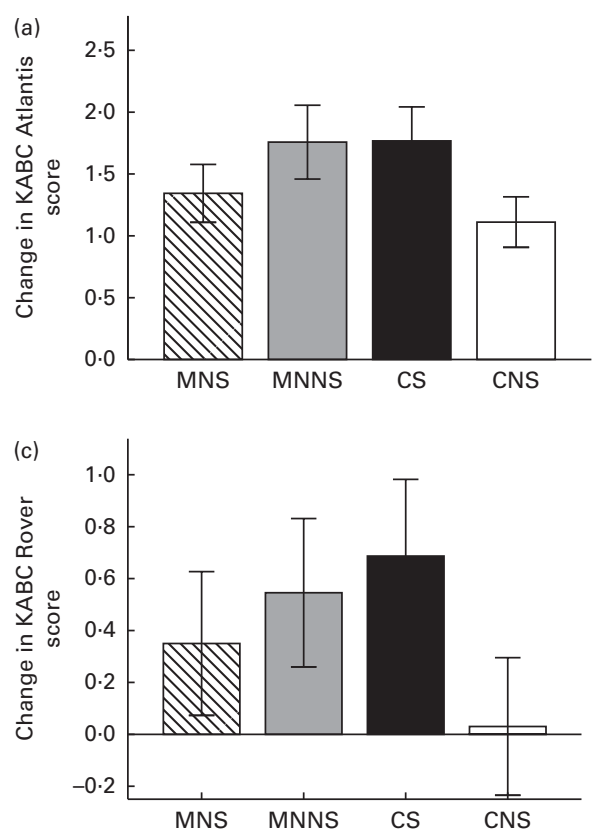

showed that the children had an adequate intake of the micronutrients vitamin $\mathrm{A}, \mathrm{Fe}$ and $\mathrm{Zn}$. Consumption of the micronutrient-fortified beverages further increased the intakes of vitamin $\mathrm{A}, \mathrm{Fe}$ and $\mathrm{Zn}$. In contrast to micronutrient intake, the mean habitual dietary energy intake did not meet the estimated energy requirements $^{(31)}$. The beverages with sugar contributed significantly to the energy intake, but not to the extent that the estimated energy requirement was reached.

The micronutrient-fortified beverages significantly increased Fe stores (SF concentration) and accordingly lowered the risk of a child being ID (SF concentration $<15 \mu \mathrm{g} /$ ) at the endpoint. Even though micronutrient fortification significantly increased $\mathrm{Hb}$ concentration at the endpoint, the prevalence of anaemia did not change from the baseline to endpoint. Only $7 \cdot 1 \%$ of the children were anaemic $(\mathrm{Hb}$ concentration $<115 \mathrm{~g} / \mathrm{l}$ ) and even less than $3 \cdot 2 \%$ of the children were IDA (Hb concentration $<115 \mathrm{~g} / \mathrm{l}$ and SF concentration $<15 \mu \mathrm{g} / \mathrm{l}$ ) at the baseline. Given that the prevalence of IDA in the study population was very low, a significant positive change in the prevalence of anaemia with micronutrient fortification was not expected. The improvements in the prevalence of ID at the endpoint, therefore, may indicate a positive shift in Fe status that is not reflected in the prevalence of anaemia observed at the endpoint. In agreement with the present results, independent studies conducted in Botswana ${ }^{(8)}$, Bangladesh $^{(34)}$ and Tanzania ${ }^{(35)}$ reported significantly higher levels of $\mathrm{Hb}$ and $\mathrm{SF}$ in subjects receiving multi-micronutrient supplements compared with the controls.

In contrast, for $\mathrm{Zn}$ status, there was an improvement in the prevalence of $\mathrm{Zn}$ deficiency regardless of the treatment group,
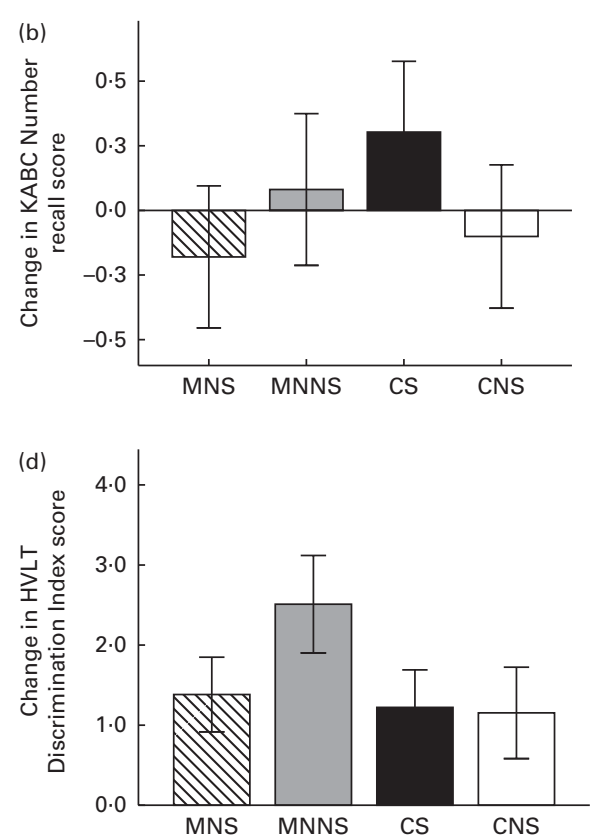

Fig. 2. Change from the baseline to endpoint in the (a) Atlantis, (b) Number recall, (c) Rover and (d) Discrimination Index test scores by treatment group. Values are means, with their standard errors represented by vertical bars. A two-factor ANCOVA was used to estimate the intervention effects of micronutrients and sugar and their interactions on endpoint measurements, adjusting for respective baseline measures, age and sex. KABC, Kaufman Assessment Battery for Children version II; MNS; beverage containing micronutrients with sugar; MNNS; beverage containing micronutrients with a non-nutritive sweetener; CS, control beverage with sugar; CNS, control beverage with a non-nutritive sweetener; HVLT, Hopkins Verbal Learning Test. (a) There were significant effects for micronutrient $(P=0.025)$ and sugar $(P=0.036)$ and the micronutrient $\times$ sugar interaction was significant $(P=0.011)$. (b) There was a significant micronutrient $\times$ sugar interaction effect $(P=0.044)$. (c) There was a significant effect for sugar $(P=0.027)$ and the micronutrient $\times$ sugar interaction was significant $(P=0.046)$. (d) There was a significant effect for micronutrient $(P=0.048)$ and a trend towards the micronutrient $\times$ sugar interaction $(P=0.062)$. 
while for that of vitamin A deficiency, no differences were observed. The present results indicated that at the baseline Zn deficiency was low and vitamin A deficiency almost non-existent with many of the children being within the normal range. When vitamin $\mathrm{A}$ and $\mathrm{Zn}$ status is adequate, SR and serum $\mathrm{Zn}$ are not sensitive indicators of vitamin $\mathrm{A}$ and $\mathrm{Zn}$ status, respectively ${ }^{(36)}$. This could explain why no significant effects of fortification were observed for $\mathrm{Zn}$ and vitamin A status.

Micronutrient fortification had a beneficial effect on the Atlantis test scores (test of learning ability and associative memory) and the Discrimination Index scores (verbal recognition memory) of the HVLT. Sugar in the form of sucrose positively influenced the Atlantis and Rover (test of simultaneous processing and visual memory) test scores. Furthermore, in the verbal recall test of the HVLT, children who received the beverages with sugar recalled 0.94 words more at Recall 3 than those who received the beverages with the non-nutritive sweetener. There was also a trend for more words recalled by children who received sugar at Recall 2 , resulting in a significant increasing effect of sugar on the mean words recalled across Recalls 1 to 3 .

In a previous South African study, provision of a multi-micronutrient-fortified biscuit resulted in improved short-term memory ${ }^{(37)}$. The authors also reported that more significant intervention effects were observed when only the children who were micronutrient deficient at the baseline were included. Similarly, in a study in the Philippines, only the children who were anaemic at the baseline $(52 \%$ of the study group) derived significant cognitive benefits from a multiple-micronutrient-fortified fruit powder beverage ${ }^{(38)}$. Positive effects of multi-micronutrient fortification on cognition have also been reported in well-nourished children. The NEMO (Nutrition Enhancement for Mental Optimization) study group ${ }^{(39)}$ reported that well-nourished school-aged children who received multi-micronutrient beverages for a year had significantly improved verbal learning and memory. As in the present study, the children included had a low prevalence of anaemia $(<14 \%)$ and IDA $(<6 \cdot 1 \%)$. Thus, the present study further strengthens previous findings that significant effects of micronutrient fortification on certain cognitive domains can be achieved even at a low prevalence of micronutrient deficiencies.

A number of studies have found that memory is improved after subjects had received a glucose drink or consumed breakfast ${ }^{(10,14,39,40)}$. Consistent with our findings, particularly cognitive tasks that require aspects of memory have been shown to be sensitive to intervention with glucose or other forms of carbohydrate ${ }^{(15,17,40)}$. Benton \& Parker ${ }^{(10)}$ reported that verbal recall memory was impaired in subjects who missed breakfast, but that these memory deficits were reversed by the consumption of either breakfast or a glucose-supplemented drink ${ }^{(10)}$ Glucose utilisation by the brain across different age periods has been studied by using 'positron emission tomography'(41) The rates of glucose usage indicate that up until the age of 16 to 18 years the cerebral cortex is metabolically maturing ${ }^{(41)}$. From birth to 4 years, the usage of glucose by the human brain increases to the extent that the glucose usage is double 


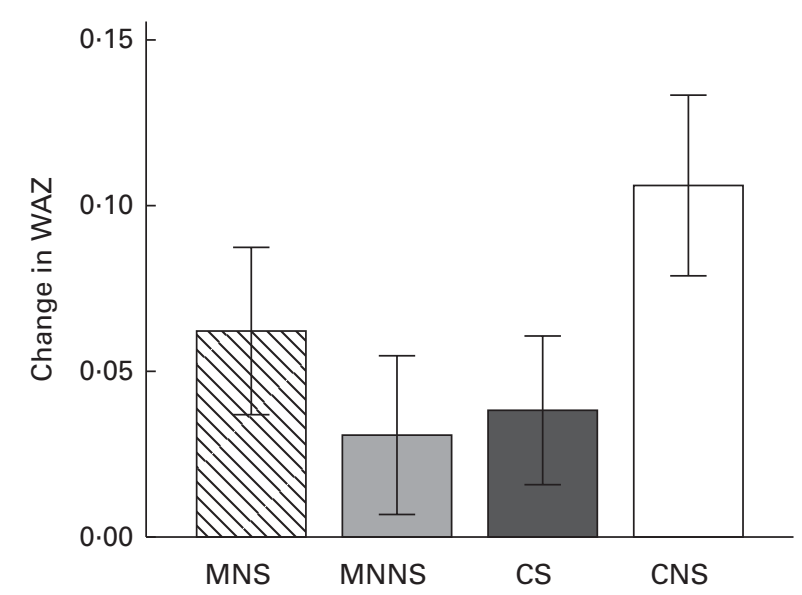

Fig. 3. Change from the baseline to endpoint in weight-for-age $z$-scores (WAZ) by treatment group. Values are means, with their standard errors represented by vertical bars. Intervention effects of micronutrients and sugar and their interactions were estimated using a two-factor ANCOVA on the endpoint measurement, adjusting for respective baseline WAZ measurement, age and sex. MNS; beverage containing micronutrients with sugar; MNNS; beverage containing micronutrients with a non-nutritive sweetener; $\mathrm{CS}$, control beverage with sugar; CNS, control beverage with a non-nutritive sweetener. There were significant effects for micronutrient $(P=0.043)$ and sugar $(P=0.026)$ and the micronutrient $\times$ sugar interaction was significant $(P=0.034)$.

the amount of adults, and the high rate of glucose consumption continues from 4 to 10 years of age ${ }^{(42)}$. This emphasises the importance of glucose for brain development and functioning and that children could particularly be highly responsive to moment-to-moment fluctuation in blood glucose levels ${ }^{(41)}$. However, there is no general consensus on the mechanisms explaining the observed beneficial effects of interventions with glucose. Various potential physiological processes have been discussed in recent reviews by Gilsenan et al. ${ }^{(43)}$ and Hoyland et al. ${ }^{(16)}$ such as the usage of glucose as a metabolic fuel for neurons, an increase in neurotransmitter synthesis as a result of increased glucose metabolism and potential peripheral action by triggering neural signals and hormones (e.g. insulin and cortisol).

However, the majority of previous studies have observed improved cognitive performance following acute intake of breakfast, carbohydrate or glucose ${ }^{(16,43)}$. To our knowledge, this is the first study to investigate the effects of long-term administration of a carbohydrate compound, sugar (sucrose), a disaccharide composed of glucose and fructose. The children who participated in the present study had energy intakes below the recommended levels and the children allocated to consume the beverages with added sugar received approximately $326 \mathrm{~kJ}$ more energy per $\mathrm{d}$ than those allocated to consume the beverages containing the non-nutritive sweetener. Thus, it is difficult to elucidate whether the observed beneficial effects of sugar in the present study were specific to sucrose or its breakdown products glucose and fructose or simply due to the increase in energy intake.

Since both micronutrients and sugar may have beneficial effects on cognitive outcomes, we expected that the combined provision of a micronutrient-fortified beverage with sugar may additively enhance the cognitive test scores. In contrast, we found significant attenuating interaction effects of micronutrients and sugar on the scores of the Atlantis, Number recall and Rover tests of the KABC as well as on the Discrimination Index of the HVLT. The interaction effects consistently indicate that micronutrients or sugar alone had a beneficial effect on some cognitive scores, but when provided in combination, the beneficial effect was attenuated. Potential mechanisms that could explain these attenuating effects are at this point unclear.

Deficits in cognitive development cannot be explained merely by poor micronutrient status. It is well recognised that cognitive performance is influenced by many factors, including sociodemographic factors such as income, crèche attendance and the education level of the mother. In the present study, all of these factors mentioned have been corrected for in the statistical analyses. Nevertheless, it is impossible to correct for all factors contributing to cognitive function.

Several steps were taken to maximise the internal validity of the study including randomisation by classroom and sex. This resulted in an equal distribution of children per treatment group at classroom, sex and school levels, removing possible bias from classroom and school environment as well as from sex. In addition, the study determined crèche attendance, income of the head of household and education level of the mother, all variables that have been shown to affect cognitive scores $^{(27)}$. When such a factor was found to significantly predict cognitive scores for a specific subtest, it was used as a covariate for the specific subtest in the statistical analyses. The results of the KABC-II and the HVLT showed similar trends. Therefore, although it is not possible to rule out chance finding in research, the results that we have observed in the present study are unlikely to be chance findings.

The mean HAZ, WAZ and BAZ of the children in all groups at the baseline were negative, $11.8 \%$ of children were stunted, $14 \%$ were underweight and $8.5 \%$ were wasted. These findings reflect a trend towards general undernutrition in the study participants. No intervention effects on HAZ and BAZ were found, although the trend for change in HAZ was in a positive direction. Similar results have been reported previously in South African children of similar age and nutritional status $^{(37)}$. A study of the effect of a fortified beverage on growth in Tanzania has shown improved growth in the intervention group, but the children were more severely undernourished, with $50 \%$ being stunted at the baseline ${ }^{(35)}$. In the present study, micronutrient fortification and sugar significantly affected only endpoint WAZ. The total mean energy intakes of all the groups were below the estimated energy requirements, although the children who received the beverages with added sugar received approximately $326 \mathrm{~kJ}$ more energy per $d$ than those who received the beverages containing the non-nutritive sweetener. Added micronutrients and sugar did not increase endpoint WAZ, but resulted in lower endpoint WAZ relative to their respective controls. Although the intervention effect on WAZ was statistically significant, all changes were small and probably not clinically important. It can be speculated that micronutrients and sugar made the children more energetic and improved their well-being, thus making them more active and as a consequence lowering their weight gain, with no effect on growth in height. Future 
trials of micronutrient fortification and energy provision (in the form of sugar) should include measurements of physical activity levels. Interestingly, we also found a significant micronutrient $\times$ sugar interaction, indicating that the decreasing effects of micronutrients and sugar on endpoint WAZ were attenuated when micronutrients and sugar were provided in combination. This interaction is similar to the attenuating micronutrient $\times$ sugar interaction effect observed on cognitive outcomes, and the underlying mechanisms need to be investigated in future research.

The low prevalence of anaemia and Fe, vitamin A and $\mathrm{Zn}$ deficiencies did not pose a limitation to the present study. Speculation remains that a higher prevalence of poor micronutrient status in the study population could have increased the likelihood of observing the effects of micronutrient fortification on more cognitive tests. A limitation of the present study is that it is impossible to elucidate whether the observed beneficial effects of sugar are specific to sucrose or to the increase in energy intake or both.

In conclusion, our data suggest that (1) both micronutrient fortification and sugar alone had beneficial effects on cognitive test scores, but when given in combination, the positive effects were attenuated, (2) both micronutrient fortification and sugar had a relative lowering effect on WAZ, but when given in combination, the lowering effect was attenuated, and (3) micronutrient fortification positively influenced $\mathrm{Hb}$, $\mathrm{SF}$ and $\mathrm{ZnPP}$ concentrations. Further research is needed to explain the mechanisms underlying the attenuating micronutrient and sugar interaction effects on cognitive function and growth and to confirm the present results.

\section{Acknowledgements}

The intervention study was supported by a research grant from Coca Cola South Africa (Pty). The company played no role in the decisions on the study design or interpretation of the results. We thank Sr Chrissie Lessing and her team for conducting all the blood sampling and the logistics of the process and assisting with baseline and end measurements. We also thank Professor S. Ellis and Dr M. van Reenen from the NWU statistical consultation services. We cordially thank the schools involved, the children, teachers and the school assistants for their hard work and contribution to the BeForMi intervention study. The authors' contributions were as follows: N. M. C. was the study director and J. C. J. the project leader; J. B. provided statistical guidance for data analysis; C. T., the MSc and PhD student on the study, was involved in all aspects of the study and article writing; all the authors provided scientific input to data interpretation and writing of the article. The authors have no conflicts of interest to report.

\section{References}

1. Labadarios D (2007) National Food Consumption SurveyFortification Baseline (NFCS-FB): South Africa, 2005. Tygerberg: University of Stellenbosch.

2. SAVACG (South African Vitamin A Consultative Group) (1995) Children Aged 6 to 71 Months in South Africa,
1994: Their Anthropometric, Vitamin A, Iron and Immunization Coverage Status. Cape Town: Isago. http://www. sahealthinfo.org.za (accessed August 2010).

3. Black MM (2003) Micronutrient deficiencies and cognitive functioning. J Nutr 133, S3927-S3931.

4. Hubbs-Tait L, Nation JR, Krebs NF, et al. (2005) Neurotoxicants, micronutrients, and social environments. Individual and combined effects on children's development. Psychol Sci Public Interest 6, 57-121.

5. Eilander A, Gera T, Sachdev HS, et al. (2010) Multiple micronutrient supplementation for improving cognitive performance in children: systematic review of randomized controlled trials. Am J Clin Nutr 91, 115-130.

6. Bryan J, Osendarp S, Hughes D, et al. (2004) Nutrients for cognitive development in school-aged children. Nutr Rev 62, 295-306.

7. Benton D (2008) Micronutrient status, cognition and behavioral problems in childhood. Eur J Nutr 47, Suppl. 3, S38-S50.

8. Abrams SA, Mushi A, Hilmers DC, et al. (2003) A multinutrientfortified beverage enhances the nutritional status of children in Botswana. J Nutr 133, 1834-1840.

9. Public Service Commission (PSC) (2008) Report on the Evaluation of the National School Nutrition Programme (NSNP). Pretoria: Creda Communications.

10. Benton D \& Parker PY (1998) Breakfast, blood glucose, and cognition. Am J Clin Nutr 67, 772S-778S.

11. Pollit E, Cueto S \& Jacoby ER (1998) Fasting and cognition in well- and undernourished schoolchildren: a review of three experimental studies. Am J Clin Nutr 67, 779S-784S.

12. Mahoney CR, Taylor HA, Kanarek RB, et al. (2005) Effect of breakfast composition on cognitive processes in elementary school children. Physiol Behav 85, 635-645.

13. Hoyland A, Dye L \& Lawton CL (2009) A systematic review of the effect of breakfast on the cognitive performance of children and adolescents. Nutr Res Rev 22, 220-243.

14. Martin PY \& Benton D (1999) The influence of glucose drink on a demanding working memory task. Physiol Behav 67, 69-74.

15. Riby LM (2004) The impact of age and task domain on cognitive performance: a meta-analytic review of the glucose facilitation effect. Brain Impairment 5, 145-165.

16. Hoyland A, Lawton CL \& Dye L (2008) Acute effects of macronutrient manipulations on cognitive test performance in healthy young adults: a systematic research review. Neurosci Biobehav Rev 32, 72-85.

17. Pollit E \& Mathews R (1998) Breakfast and cognition: an integrative summary. Am J Clin Nutr 67, 804S-813S.

18. Ogunlade AO, Kruger HS, Jerling JC, et al. (2011) Point-ofuse micronutrient fortification: lessons learned in implementing a preschool-based pilot trial in South Africa. Int J Food Sci Nutr 62, 1-16.

19. Catignani GL \& Bieri JG (1983) Simultaneous determination of retinol and $\alpha$-tocopherol in serum or plasma by liquid chromatography. Clin Chem 29, 708-712.

20. World Health Organization (2007) Joint World Health Organization/Center for Disease Control and Prevention Technical Consultation on the Assessment of Iron Status at the Population Level. Geneva: WHO.

21. Thurnham DI, McCabe LD, Haldar S, et al. (2010) Adjusting plasma ferritin concentrations to remove the effects of subclinical inflammation in the assessment of iron deficiency: a meta-analysis. Am J Clin Nutr 92, 546-555.

22. World Health Organization (2011) Serum Retinol Concentration for Determining the Prevalence of Vitamin A Deficiency in Populations. Vitamin and Mineral Nutrition 
Information System. Geneva: WHO (WHO/NMH/NHD/ MNM/11.3). http://www.who.int/vmnis/indicators/retinol. pdf (accessed 10 October 2012).

23. Kongsbak K, Wahed MA, Friis H, et al. (2006) Acute-phase protein levels, diarrhoea, Trichuris trichiura and maternal education are predictors of serum retinol: a cross-sectional study of children in a Dhaka slum, Bangladesh. Br J Nutr 96, 725-734.

24. International Zinc Nutrition Consultative Group (IZiNCG) (2004) Assessment of the risk of zinc deficiency in populations and options for its control. Food Nutr Bull 25, S99-S203.

25. Kaufman AS, Lichtenberger EO, Fletscher-Janzen E, et al. (2005) Essentials of KABC-II Assessment. New Jersey: John Wiley \& Sons, Inc.

26. Bangirana P, Seggane-Musisi, Allebeck P, et al. (2009) A preliminary examination of the construct validity of the KABC-II in Ugandan children with a history of cerebral malaria. Afr Health Sci 9, 186-192.

27. Bangirana P, John CC, Idro R, et al. (2009) Socioeconomic predictors of cognition in Ugandan children: implications for community interventions. PLoS One 4, e7898.

28. Kaufman AS \& Kaufman NL (2004) Kaufman Assessment Battery for Children, 2nd ed. Circle Pines: AGS Publishing.

29. Lacritz LH \& Cullum CM (1998) The Hopkins Verbal Learning Test and CVLT: a preliminary comparison. Arch Neuropsyc 13, 623-228.

30. Foxcroft C \& Roodt G (2009) Introduction to Psychological Assessment in the South African Context. Cape Town: Oxford University Press Southern Africa.

31. Institute of Medicine of the National Academics (2006) Dietary Reference Intakes: The Essential Guide to Nutrient Requirements [JF Otten, HP Hellwig and LD Meyers, editors]. Washington, DC: The National Academic Press.

32. National Academy of Sciences (1989) Recommended Dietary Allowances. Washington, DC: The National Academic Press.

33. Labadarios D \& Louw R (2007) Selected micronutrient status, iron status. In National Food Consumption Survey-Fortifica- tion Baseline (NFCS-FB): South Africa, 2005, pp. 447-455 [D Labadarios, editor]. Tygerberg: University of Stellenbosh.

34. Hyder SMZ, Haseen F, Khan M, et al. (2007) A multiplemicronutrient-fortified beverage affects haemoglobin, iron and vitamin A status and growth in adolescent girls in rural Bangladesh. J Nutr 137, 2147-2153.

35. Ash DM, Tatala SR, Frongillo EA, et al. (2003) Randomized efficacy trial of a micronutrient-fortified beverage in primary school children in Tanzania. Am J Clin Nutr 77, 891-898.

36. Gibson RS (2005) Principles of Nutritional Assessment, 2nd ed. New York: Oxford University Press.

37. Van Stuijvenberg ME, Kvasvig JD, Faber M, et al. (1999) Effect of iron-, iodine-, and $\beta$-carotene-fortified biscuits on the micronutrient status of primary school children: a randomized controlled trial. Am J Clin Nutr 69, 497-503.

38. Solon FS, Sarol JN, Bernardo ABI, et al. (2003) Effect of a multiple-micronutrient-fortified fruit powder beverage on the nutrition status, physical fitness, and cognitive performance of schoolchildren in the Philippines. FNB 24, Suppl. 4, S129-S140

39. Osendarp SJM, Baghurst KI, Bryan J, et al. (2007) Effect of a 12-mo micronutrient intervention on learning and memory in well-nourished and marginally nourished school-aged children: 2 parallel, randomized, placebo-controlled studies in Australia and Indonesia. Am J Clin Nutr 86, 1082-1093.

40. Benton D \& Stevens MK (2008) The influence of a glucose containing drink on the behaviour of children in school. Biol Psychol 78, 242-245.

41. Chugani HT (1998) A critical period of brain development: studies of cerebral glucose utilization with PET. Prev Med 27, 184-188.

42. Bellise $\mathrm{F}$ (2004) Effects of diet on behaviour and cognition in children. Br J Nutr 92, S227-S232.

43. Gilsenan MB, de Bruin EA \& Dye L (2009) The influence of carbohydrate on cognitive performance: a critical evaluation from the perspective of glycaemic load. Br J Nutr 101, 941-949. 